\title{
EDUCAR PARA A SUSTENTABILIDADE: UM ESTUDO DE CAMPO SOBRE OS REFLEXOS GERADOS PELA EDUCAÇÃO SUSTENTÁVEL
}

\author{
EDUCATIONFOR SUSTAINABILITY: A FIELD STUDY \\ ON THE REFLECTIONS GENERATED BY SUSTAINABLE EDUCATION
}

\author{
BONASSINA, Ana Lucia Berno ${ }^{1}$ \\ KUROSHIMA, Katia Naomi²
}

\begin{abstract}
RESUMO
Este trabalho se propôs a avaliar o impacto da educação sustentável por meio do estudo de campo com jovens em vulnerabilidade socioeconômica. $\mathrm{O}$ artigo estabelece uma pesquisa com estudantes do $8^{\circ}$ e $9^{\circ}$ ano do Ensino Fundamental, e $1^{\circ}$ ano e $2^{\circ}$ ano do Ensino Médio de escolas do município de Itajaí (SC), vinculados a um Projeto de Extensão Universitária sobre Educação Ambiental. Inicialmente, realizou-se a aplicação do questionário visando avaliar o conhecimento prévio dos estudantes sobre a temática. Uma vez por mês, durante sete meses, os alunos participaram de atividades planejadas e executadas por acadêmicos e professores do Curso de Oceanografia que abordavam a temática sustentabilidade ambiental. Esses momentos objetivavam desenvolver um cidadão consciente do ambiente de maneira integral, de forma a estar preocupado com os problemas associados a ele e que tenha o conhecimento, as atitudes, motivações, envolvimento e habilidades para trabalhar individual e coletivamente em busca de soluções para resolver os problemas ambientais atuais e prevenir os futuros. Ao término dos encontros realizouse uma nova aplicação do questionário. A análise dos dados obtidos possibilitou a elaboração das considerações a respeito do projeto e de seus reflexos na vivência dos estudantes. O projeto serviu como motivação aos estudantes para adotarem um posicionamento sustentável com ações que visem à preservação do meio ambiente. No entanto, a temática sustentabilidade não deve estar restrita somente a esses momentos propostos, mas sim ser trabalhada de forma continuada durante todos os anos escolares de maneira interdisciplinar, auxiliando, assim, na formação de cidadãos íntegros e conscientes ambientalmente.
\end{abstract}

Palavras-chave: Sustentabilidade; Educação; Ética; Cidadania; Projeto de Extensão.

1 Universidade do Vale do Itajaí - UNIVALI. Itajaí, PR, Brasil. / Instituto Federal de Educação, Ciência e Tecnologia do Paraná - IFPR. Curitiba, PR, Brasil. ORCID: https://orcid.org/0000-0001-5279-0823 e-mail: ana.bonassina@ifpr.edu.br

2 Universidade do Vale do Itajaí - UNIVALI. Itajaí, PR, Brasil. ORCID: https://orcid.org/0000-0002-42619878 e-mail: kuroshima@univali.br 
DOI: $10.12957 /$ e-mosaicos.2021.50343

\section{ABSTRACT}

This work has been proposed to evaluate the impact of sustainable education by means of a field study with young people in socio-economic vulnerability. The article establishes a research with students of the 8th and 9th grade of elementary School, and 1st year and 2nd year of high school in the city of Itajaí (SC), linked to a university extension project on environmental education. Initially, the questionnaire was applied in order to obtain the student's previous knowledge about the theme. Once a month, for seven months, the students participated in planned and performed activities by academics and professors of the oceanography course that addressed the thematic environmental sustainability. These moments aimed to develop a citizen conscious of the environment in an integral way, so as to be concerned with the problems associated with this environment and that has the knowledge, attitudes, motivations, involvement and skills to work Individually and collectively in search of solutions to solve current environmental problems and prevent future ones. At the end of the meetings, a new application of the questionnaire was carried out. With the analysis of the data obtained it became possible to elaborate the considerations regarding the project and its reflections in the students ' experience. The project served as a motivation for students to adopt a sustainable positioning with actions aimed at preserving the environment. However, the thematic sustainability should not be restricted only to these proposed moments, but rather be worked on continuously throughout the school years in an interdisciplinary way, thus assisting in the formation of healthy citizens and Environmentally conscious.

KeYwords: Sustainability; Education; Ethic; Citizenship; Extension Project.

\section{INTRODUÇÃO}

O conceito de sustentabilidade tem sido cada vez mais discutido em todo o cenário social, o incentivo ao progresso e ao crescimento ilimitado ocasionaram inúmeras consequências, as quais evidenciaram a preocupação com o meio ambiente para a continuidade das gerações futuras (SILVA, 2005, p.12).

Na contemporaneidade, observa-se que as práticas sustentáveis estão sendo cada vez mais incentivadas em resposta aos eventos ocorridos, dentre eles, inundações, terremotos, incêndios, pobreza extrema, escassez dos recursos naturais e mudanças climáticas entre tantos outros. No entanto, apesar da solidariedade da comunidade após alguns destes episódios, raramente observa-se a conscientização de que estas catástrofes ambientais decorrem de dois percursos, ou ser vítima da transformação da natureza ou ser cúmplice neste processo de transformação (CARRAMILLO-GOING e CORTELLA, 2017). Para encontrar harmonia ao impasse estabelecido ao longo dos séculos, entre 0 
DOI: $10.12957 /$ e-mosaicos.2021.50343

desenvolvimento e a preservação do meio ambiente, a Educação Ambiental é uma possível estratégia para incentivar uma nova conduta ética (CAPRA, 2006), pois permite por meio de uma série de vivências educacionais uma efetiva transformação de contextos, realidades e "visões de mundo" que proporcionam uma compreensão das complexidades da dimensão educativa e a relevância de uma percepção sensível/inteligível para uma ressignificação do meio ambiente (HOFFMANN, LAMAS e WESTPHAL, 2019) através de uma Educação Ambiental crítica-transformadora (TOZONI-REIS, 2008).

Por outro lado, a nova ética ambiental, intrinsicamente associada à educação ambiental, busca desenvolver um cidadão consciente de seu ambiente e de maneira integral, de forma a estar preocupado com os problemas associados a esse ambiente e com conhecimento, atitudes, motivações, envolvimento e habilidades para trabalhar individual e coletivamente em busca de soluções para resolver os problemas atuais e prevenir os futuros (VIVEIROS et al., 2015).

A realização desse trabalho se justifica, portanto, pela necessidade de contribuir com pesquisas de campo que promovam a educação para a sustentabilidade, ressaltando a importância de se analisar as transformações no conhecimento e na consciência sustentável dos estudantes após o contato com a nova ética ambiental, por meio da Educação Ambiental crítico-transformadora. Ademais, mostra-se necessária a análise sintética dos dados coletados, expondo-os de uma forma coesa e objetiva, visando avaliar como ações de educação ambiental continuada podem ser transformadores em todos os atores envolvidos.

Logo, o presente artigo discute possíveis caminhos para viabilizar a educação sustentável em instituições de ensino por meio da abordagem da temática em sala de aula, em espaços não escolares de maneira sistematizada e apoiada na extensão universitária. Além disso, objetiva analisar os reflexos que a educação sustentável promove aos sujeitos no que diz respeito aos conhecimentos e à consciência ambiental, analisando suas ações em ambientes cotidianos, bem como o seu entendimento sobre a temática.

\section{Referencial teóRico - Desenvolvimento SUSTENTÁvel}

Segundo Valle e Souza (2014), o sistema de produção atual necessita de inúmeros recursos naturais, sendo muitos desses não renováveis. O grande crescimento da industrialização e da população no século XX impulsionou o consumo desenfreado dos recursos naturais. Tal consumo, também presente no século XXI, nos traz a uma crise ambiental que coloca todos em risco, pois além de se utilizar desses recursos sem 
DOI: $10.12957 /$ e-mosaicos.2021.50343

consciência, os resíduos gerados pela sua transformação são descartados de maneira equivocada, causando a poluição de rios, solo, ar e oceanos.

Todavia, Valle e Souza (2014) ressaltam que uma saída para esta crise ambiental está no desenvolvimento sustentável, que nos permite crescer e cuidar do meio ambiente, utilizando-o no presente, concomitantemente, preservando-o para as próximas gerações. Esse novo olhar é a chave para a continuidade da humanidade, ou seja, deixar de atentar apenas às questões financeiras e econômicas e passar a englobar critérios sociais e ambientais em suas decisões.

Para Pereira et al. (2013) algumas mudanças são primordiais para criar uma sociedade mais sustentável, pois não há como manter a atual forma de consumo desenfreado, sendo necessário um repensar global, em busca de uma sociedade mais igualitária. É preciso que a distribuição de recursos ocorra de forma adequada para garantir as necessidades humanas essenciais, assim sendo, todos deverão cooperar e trabalhar juntos, conscientes da responsabilidade dos impactos ambientais ocasionados pelas ações individuais e coletivas. Conforme menciona Boff:

Estamos diante de um momento crítico da história da Terra, numa época em que a humanidade deve escolher o seu futuro [...]. A escolha é nossa e deve ser: ou formar uma aliança global para cuidar da Terra e cuidar uns dos outros, ou arriscar a nossa destruição e a destruição da diversidade da vida (CARTA DA TERRA, 1992, apud, BOFF, 2012, p. 7).

No cenário repleto de crises ambientais e com futuro incerto em que se encontra o planeta Terra, Boff (2012) observa que a sustentabilidade é a chave para controlar e reverter tal situação. No entanto, antes de aprofundar a temática torna-se necessário entender o conceito que permeia a sustentabilidade. De acordo com o autor, o termo pode ser definido como:

O conjunto dos processos e ações que se destinam a manter a vitalidade e integridade da mãe Terra, a preservação de seus ecossistemas com todos os elementos químicos, físicos e ecológicos que possibilitam a existência e reprodução da vida, o atendimento das necessidades da presente e das futuras gerações, e a continuidade, a expansão e a realização das potencialidades da civilização humana em suas várias expressões (BOFF, 2012, p. 10). 
DOI: $10.12957 /$ e-mosaicos.2021.50343

Silva (2005, p. 11) congrega com Boff (2012) ao afirmar que a sustentabilidade remete à preocupação da existência e manutenção dos recursos naturais com possibilidade de um ambiente propício para continuidade das gerações futuras. Essa abordagem permite vislumbrar que, mesmo vivenciando episódios de catástrofes naturais tais como incêndios, queimadas, rompimento de barragens, vazamentos de petróleo, entre outros, de maneira constante, pouco tem sido feito para promover a conscientização a respeito da sustentabilidade.

Segundo Boff (2012), para que se efetive a árdua tarefa de desenvolver e vivenciar um modo de vida sustentável a nível global faz-se urgente uma transformação planetária. Logo, é preciso alterar as ações atuais e passar a enxergar as causas dos desastres ambientais para que compreendendo-as, se vislumbrem novas soluções. Além disso, devese compreender que 0 conceito de sustentabilidade não pode ser reduzido ao crescimento/desenvolvimento. Esse conceito deve subsidiar toda a realidade, abrangendo desde as pessoas, as comunidades, a cultura, a política, a indústria, as cidades e a educação. Diante desse pensamento, sustentabilidade caracteriza-se como "um modo de ser e de viver que exige alinhar as práticas humanas às potencialidades limitadas de cada bioma e às necessidades das presentes e das futuras gerações" (BOFF, 2012, p. XX).

\section{A EDUCAÇÃO PARA A SUSTENTABILIDADE}

A Conferência das Nações Unidas para o Meio Ambiente Humano (CNUMAH), realizada em Estocolmo, em 1972, evidenciou um grande passo no debate sobre os problemas ambientais e sociais em nível global. Nesse encontro, elaborou-se a Declaração sobre o Ambiente Humano, composta por 26 princípios que orientam a construção de ambientes que permitam ao ser humano gozar de todos os seus direitos naturais, bem como equilibrar os aspectos humanos e naturais. Segundo o princípio 1 do documento:

O homem tem o direito fundamental à liberdade, à igualdade e ao desfrute de condições de vida adequadas em um meio ambiente de qualidade tal que Ihe permita levar uma vida digna e gozar de bem-estar, tendo a solene obrigação de proteger e melhorar o meio ambiente para as gerações presentes e futuras (CNUMAH, 1972, Princípio 1, p. 1).

Diante disso, mesmo que implicitamente, o conceito de sustentabilidade anteriormente mencionado por Boff (2012) e Silva (2005) - passa a integrar todos os 
DOI: $10.12957 /$ e-mosaicos.2021.50343

fóruns relacionados à temática de desenvolvimento e meio ambiente. Tendo por base essa declaração, a Unesco e o Programa das Nações Unidas para o Meio Ambiente (Pnuma) criaram o Programa Internacional de Educação Ambiental (Piea), com o objetivo de promover o intercâmbio de ideias, informaç̧ões e experiências em educação ambiental entre as nações de todo o mundo (BARBIERI; SILVA; 2011).

Ao fim de 1975, como uma resposta à Conferência de Estocolmo, a UNESCO realizou, em Belgrado, o Seminário Internacional sobre Educação Ambiental que produziu a Carta de Belgrado - um dos mais evidentes documentos da década - que trouxe ao debate a necessidade de uma nova ética ambiental (GOTTARDO, 2003). Conforme este documento, a meta da Educação Ambiental (EA) é promover o desenvolvimento de um cidadão consciente do ambiente e de maneira integral, de forma a estar preocupado com os problemas associados a esse ambiente e que tenha o conhecimento, as atitudes, motivações, envolvimento e habilidades para trabalhar individual e coletivamente em busca de soluções para resolver os problemas atuais e prevenir os futuros. Esse documento fortificou a necessidade de uma nova ética ambiental global, e proporcionou a crença na erradicação de problemas seculares que assolam o planeta como a fome, a pobreza, o analfabetismo, a poluição e a exploração humana (DIAS, 2003).

É nesse contexto, carregado de problemas e esperanças, que a educação para a sustentabilidade torna-se um importante instrumento de apropriação crítica e reflexiva de conhecimentos, atitudes, valores e comportamentos para a conscientização, que busca formar além de estudantes, cidadãos capazes de observar o meio em que vivem; refletir sobre os problemas existentes no entorno e procurar solucioná-los de forma eficaz para a construção de uma sociedade sustentável nas dimensões ambiental e social (TOZONIREIS, 2008). Busca conscientizar, ainda, sobre a importância do cuidado e da prevenção, refletindo que muitos danos ambientais não podem ser revertidos ou levam séculos para reversão.

A cultura da sustentabilidade deve ser orientada pelos seguintes princípios pedagógicos:

1. Educar para pensar globalmente: para transformar o nível local e global; enxergar, pensar e refletir sobre os problemas que assolam o mundo, "Educar para não ser omisso, indiferente e nem conivente com a destruição da vida em qualquer parte do planeta".

2. Educar para os sentimentos: ensinar a sentir e a ter sentido, a ver-se como parte de um todo que ainda está em construção; 
DOI: $10.12957 /$ e-mosaicos.2021.50343

3. Ensinar a identidade Terrena: como nossa condição humana essencial, devemos compartilhar com todos a vida no planeta, sendo, portanto, ao mesmo tempo individual e coletiva. Educar para amar a Terra e não para explorá-la como fonte inesgotável de recursos.

4. Formar para a consciência planetária: compreender que somos interdependentes;

5. Formar para a compreensão: formar para a ética do gênero humano, não para a ética instrumental e utilitária do mercado. Ensinar a comunicação visando a compreensão e não a indução e subordinação;

6. Educar para a simplicidade voluntária: devemos ensinar a agir, a escolher um mundo mais responsável frente à cultura de consumo e de guerra que encontramos atualmente. Devemos passar da responsabilidade diluída para a ação concreta, compartilhada, praticando a sustentabilidade em todos os setores de nossa vida (GADOTTI, 2008).

Com essas constatações, nota-se que a educação ambiental se mostra revolucionária na concretização de uma nova ética ambiental por décadas almejada.

\section{MÉTOdO}

O presente trabalho fez uso da pesquisa exploratória, quanto aos fins, uma vez que se procura entender melhor o que será estudado, aumentando o conhecimento sobre o assunto. Segundo Gil (2010), tais pesquisas proporcionam maior familiaridade com o problema que está sendo estudado, procurando torná-lo mais esclarecedor ou construir hipóteses. O planejamento pode ser flexível, uma vez que se atenta para vários aspectos referentes ao fato estudado.

Em relação aos meios e procedimentos, utilizou-se a pesquisa de campo, cujos questionários foram entregues aos estudantes no ambiente escolar. Para Lakatos e Marconi (2001) a pesquisa de campo é utilizada em uma visão focada no entendimento de vários aspectos da sociedade, estudando-se para tantos indivíduos, grupos, comunidade, organizações, entre outros. Ela é utilizada para a obtenção de informações e conhecimento a respeito de determinado problema, podendo trazer uma resposta, hipótese ou a descoberta de novas ocorrências, ou ainda a relação entre todos os pontos mencionados. 
DOI: $10.12957 /$ e-mosaicos.2021.50343

Quanto à abordagem, caracteriza-se como uma pesquisa qualitativa, uma vez que se procura com este trabalho fazer uma avaliação mais ampla e detalhada da situação em que se encontra o problema de estudo em tal ambiente.

Em princípio, podemos afirmar que, em geral, as investigações que se voltam para uma análise qualitativa têm como objeto situações complexas ou estritamente particulares. Os estudos que empregam uma metodologia qualitativa podem descrever a complexidade de determinado problema, analisar a interação de certas variáveis, compreender e classificar processos dinâmicos vividos por grupos sociais, contribuir no processo de mudança de determinado grupo e possibilitar, em maior nível de profundidade, o entendimento das particularidades do comportamento dos indivíduos (RICHARDSON, 2014, p. 84).

O trabalho se desenvolveu com base na coleta de dados e desenvolvimento de um projeto sobre educação sustentável, denominado Projeto Oceanos (PO), correspondente a uma atividade de extensão universitária vinculada à Universidade do Vale do Itajaí (UNIVALI) que se propõe a trabalhar com educação ambiental. O PO iniciou suas atividades em 2015 e, atualmente, vem atuando com estudantes do Ensino Médio do Instituto Crescer (IC) ${ }^{3}$. Durante o ano de 2018, ano de referência deste artigo, foram realizadas 7 (sete) atividades para 8 turmas de aproximadamente 25 estudantes cada turma. Assim, os encontros foram organizados de forma com que cada estudante participasse das atividades uma vez ao mês com duração de quatro horas cada encontro. As atividades focaram o tema central do projeto, ou seja, sustentabilidade e preservação do meio ambiente e foram aplicadas mensalmente entre os meses de março a novembro2018, tendo como conteúdos norteadores conceitos sobre a água, vivências e resgate de memórias e provocações de sentimentos, atividades relacionadas a resíduos, atividades abordando conhecimentos sobre micro e macro organismos, visita ao Museu Oceanográfico de Piçarras - SC e atividade objetivando polinizar o conhecimento construído durante o processo de formação. Importante destacar que as atividades foram desenvolvidas para serem trabalhadas como uma "viagem de descobertas" se constituindo em conteúdos curriculares ao longo da caminhada.

30 Instituto Crescer é uma empresa sem fins lucrativos que visa preparar estudantes do Ensino Médio para o primeiro emprego. Assim, o IC seleciona estudantes em situação de vulnerabilidade social e promove atividades diversas (Comunicação Oral e Escrita; Ética; Cidadania; Relações Interpessoais; Matemática e Conhecimentos sobre Sustentabilidade) para alcançar seus objetivos, dentre eles, o conhecimento à sustentabilidade. 
DOI: $10.12957 /$ e-mosaicos.2021.50343

Importante esclarecer que os estudantes foram informados sobre 0 desenvolvimento das atividades ao longo do processo e, junto aos seus responsáveis, assinaram termo de consentimento e aquiescência para participação nas atividades. A coleta de dados foi realizada em formulário e com roteiro estruturado, em dois momentos: antes da realização do projeto e ao seu término. 0 instrumento era composto por 14 (quatorze) perguntas, sendo 10 questões de múltipla escolha, 2 (duas) dicotômicas e 2 (duas) com respostas abertas. $O$ instrumento de coleta de dados utilizado foi estruturado sobre duas dimensões: conhecimento e educação sustentável; consciência sustentável. 0 questionário foi aplicado em sala de aula, em horário disponibilizado pela direção do IC. Os formulários eram anônimos, constando apenas perguntas sobre 0 tema sustentabilidade, sendo evitado qualquer tipo de informação pessoal.

Em um primeiro contato com os estudantes, apresentou-se a equipe do projeto Oceanos (composta por professores, doutorandos e acadêmicos da universidade) e solicitou-se o preenchimento do questionário, sem lhes passar informação alguma a respeito das próximas ações. Essa coleta inicial de dados, realizada em fevereiro de 2018, objetivou recolher informações sobre a consciência e conhecimento sustentável que os estudantes possuíam até o momento. Na sequência, realizou-se o projeto pré-elaborado no qual os estudantes participavam de aulas com a temática sustentabilidade uma vez ao mês. As aulas eram realizadas por uma equipe de aproximadamente dez pessoas que se revezavam e administravam esses momentos. Além do grupo formado, havia outros professores, não ligados ao projeto Oceanos, que assistiam as aulas junto aos estudantes e abordavam a temática em suas aulas, realizando um aprendizado interdisciplinar. 0 segundo questionário foi realizado em novembro de 2018 com os estudantes que participaram do projeto e que ainda estavam frequentando o curso no contraturno. Com a obtenção dos dados, seguiu-se a elaboração das inferências estatísticas, com a realização de uma análise de médias.

\section{Resultados dA PEsquisa - CARACTERIZAÇÃo dOS estudantes}

Participaram dessa pesquisa os estudantes de Educação Básica de escolas situadas na região do Vale do Itajaí. No primeiro momento, 206 estudantes responderam o questionário, enquanto que, no segundo momento, 133 estudantes realizaram o preenchimento. A seleção dos alunos foi realizada pelo IC, responsável pela logística das atividades, havendo como pré-requisitos a permanência na escola durante todo o período das atividades e estar em vulnerabilidade socioeconômica. Por isso, as atividades eram realizadas com alunos de diferentes escolas e diferentes idades, em grupos de aproximadamente 25 alunos. Cada atividade era assim, repetida oito vezes ao longo do 
DOI: $10.12957 /$ e-mosaicos.2021.50343

mês, ocupando duas semanas de atividades, para contemplar todos os alunos deste programa.

\section{ANÁLISE dOS RESULTADOS}

Visando propor uma análise lógica e estruturada sobre os dados obtidos, as questões que compunham o questionário foram separadas em dois construtos, sendo eles: 1 - conhecimento e educação sustentável e 2 - consciência sustentável. 0 primeiro relaciona os questionamentos direcionados às aprendizagens teóricas e conhecimentos sobre a temática, contemplando 4 (quatro) questões objetivas enquanto o segundo busca inferir a prática de ações sustentáveis pelos estudantes, contemplando 5 (cinco) questões. As 5 (cinco) demais questões do questionário destinavam-se à avaliação do PO, bem como a solicitação de sugestões de melhoria para as próximas edições.

CONSTRUTO: CONHECIMENTO E EDUCAÇÃO SUSTENTÁVEL

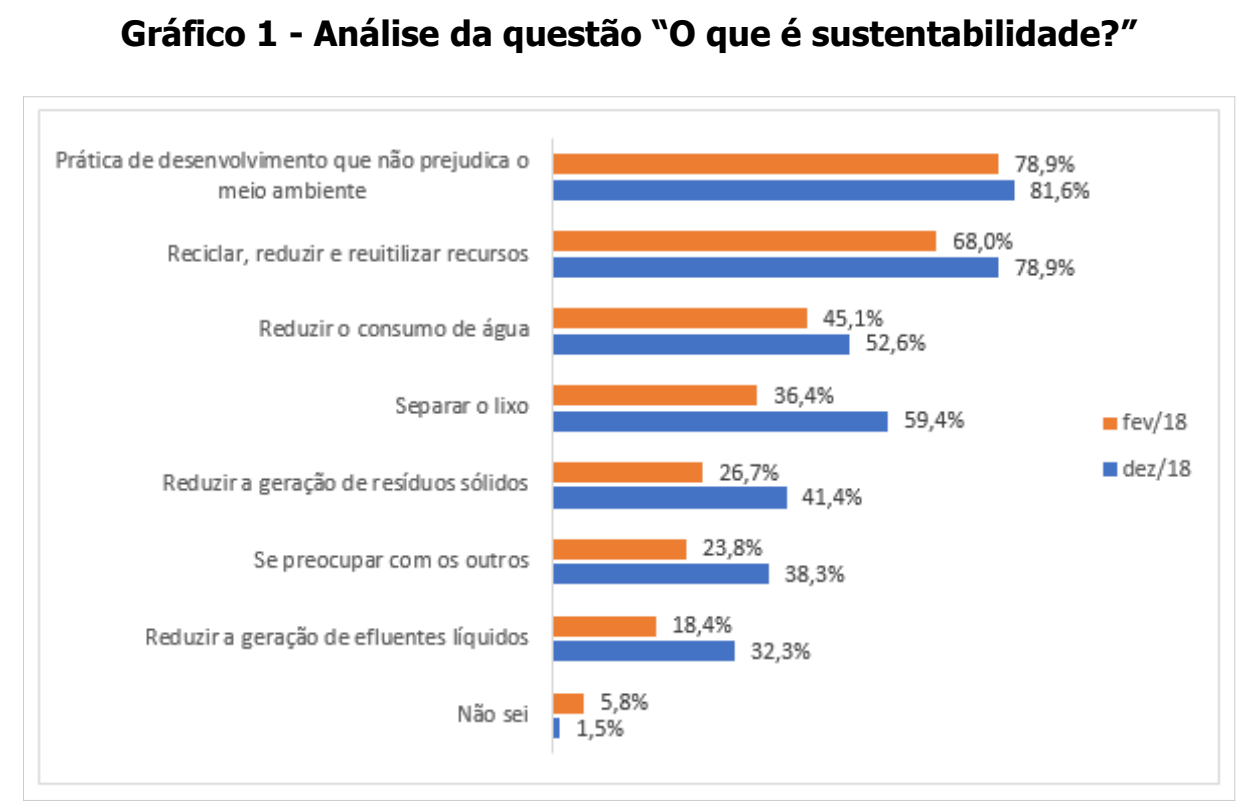

Fonte: Autor (2019) 
DOI: $10.12957 / \mathrm{e}-\mathrm{mosaicos} .2021 .50343$

O Gráfico 1 demonstra a coleta de dados obtida com a aplicação do questionário na questão referente à pergunta "O que é sustentabilidade" e os alunos poderiam marcar quantas opções desejassem. Os resultados mostram que "Prática de desenvolvimento que não prejudica o meio ambiente" foi a opção mais votada antes $(81,6 \%)$ e depois das intervenções $(78,9 \%)$. No entanto, considerando que em dezembro nem todos os alunos conseguiram responder, pode ser que esta diferença seja em função daqueles não responderam. Por outro lado, diante dos dados pode-se observar que houve alterações significativas na concepção dos estudantes para algumas questões pouco pontuadas antes das intervenções, como "separar o lixo", com aumento de $23 \%$, passando de $36,4 \%$ para $59,4 \%$ após as intervenções. Este resultado demonstra que as atividades trabalhadas envolvendo o lixo marinho foram significativas. Durante as atividades, este tema foi trabalhado em mais de um momento de forma transversal, seja durante a dinâmica do Lixo, ou do uso da água, como durante as aulas de micro e macro organismos marinhos, considerando que os temas sempre foram em torno da sustentabilidade. Oportuno observar o aumento de $15 \%$ para a questão "se preocupar com os outros", evidenciando como as relações interpessoais passaram a ser importantes para a questão da sustentabilidade, uma vez que o homem não pode ser dissociado do seu "Lar Terra" (CARRAMILLO-GOING e CORTELLA, 2017). Mesmo que apenas 38,3\% tenha votado neste item após o término do projeto sustentabilidade, este resultado já demonstra grandes mudanças e o alcance destas atividades na percepção dos alunos quanto ao tema sustentabilidade e ao seu entorno. Tal fato evidencia-se na alteração do conceito de sustentabilidade que os estudantes possuíam anteriormente, e a nova conceituação entendida com a participação do projeto. Além disso, a porcentagem de estudantes que mencionaram não saber responder o questionamento caiu em 4,32\%, em relação ao primeiro questionário respondido, sendo que apenas $1,5 \%$, ou seja, 2 alunos, não souberam responder esta questão. 
DOI: $10.12957 / \mathrm{e}-\mathrm{mosaicos} .2021 .50343$

Gráfico 2 - Em sua opinião, quais os principais problemas relacionados à sustentabilidade do país?

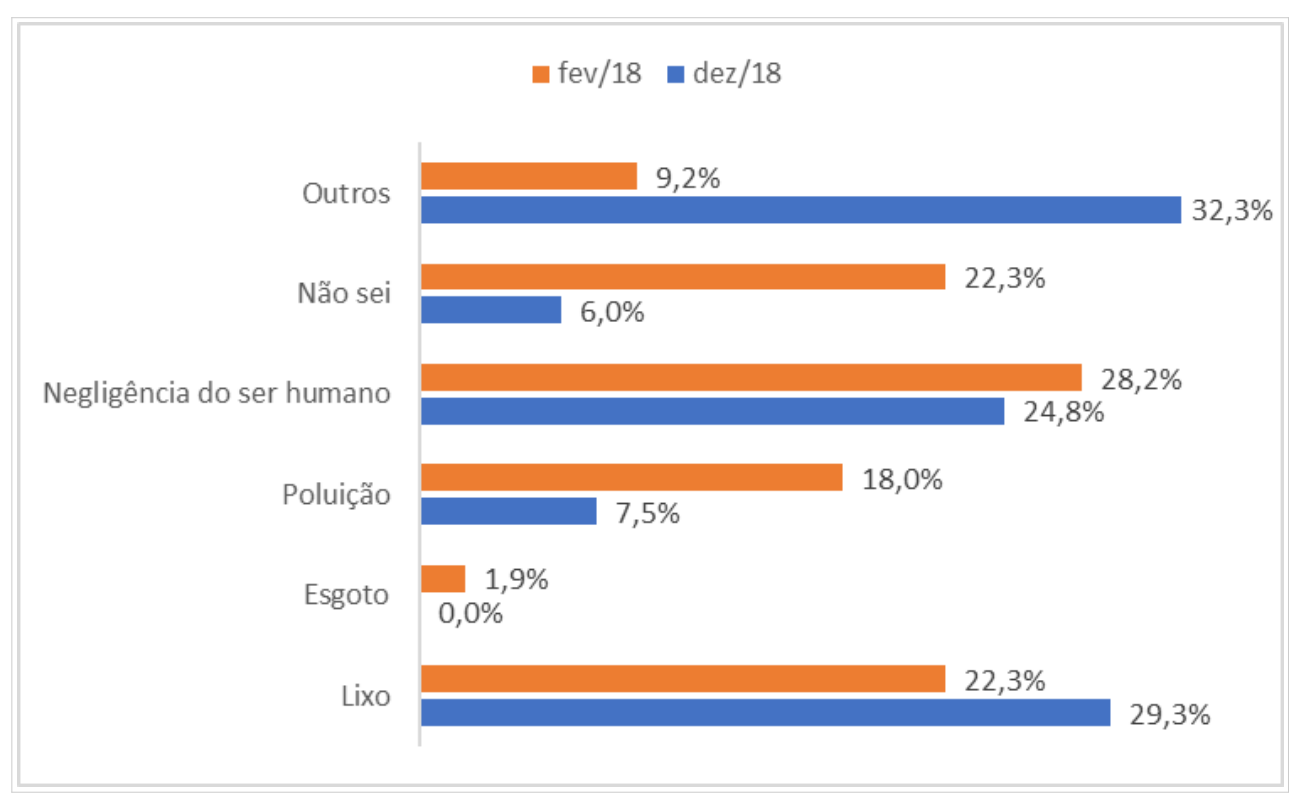

Fonte: Autor (2019)

Com a observação dos dados dispostos no Gráfico 2, pode-se constatar que após a elaboração do projeto sustentabilidade, os estudantes reanalisaram a situação ambiental do nosso país, sendo que tal reflexão promoveu a ampliação do entendimento sobre a gravidade dos problemas ambientais, bem como a constatação de novos problemas anteriormente não mencionados. Tal fato encontra-se em destaque no aumento da porcentagem $(23,11 \%)$ de outros problemas -citados pelos estudantes- relacionados à sustentabilidade, em relação aos dados obtidos no primeiro questionário. 
DOI: $10.12957 /$ e-mosaicos.2021.50343

Gráfico 3 - Numa escala de 1 a 10, qual o seu grau de conhecimento sobre os temas abaixo:

(1 para baixo conhecimento e 10 para alto conhecimento.)

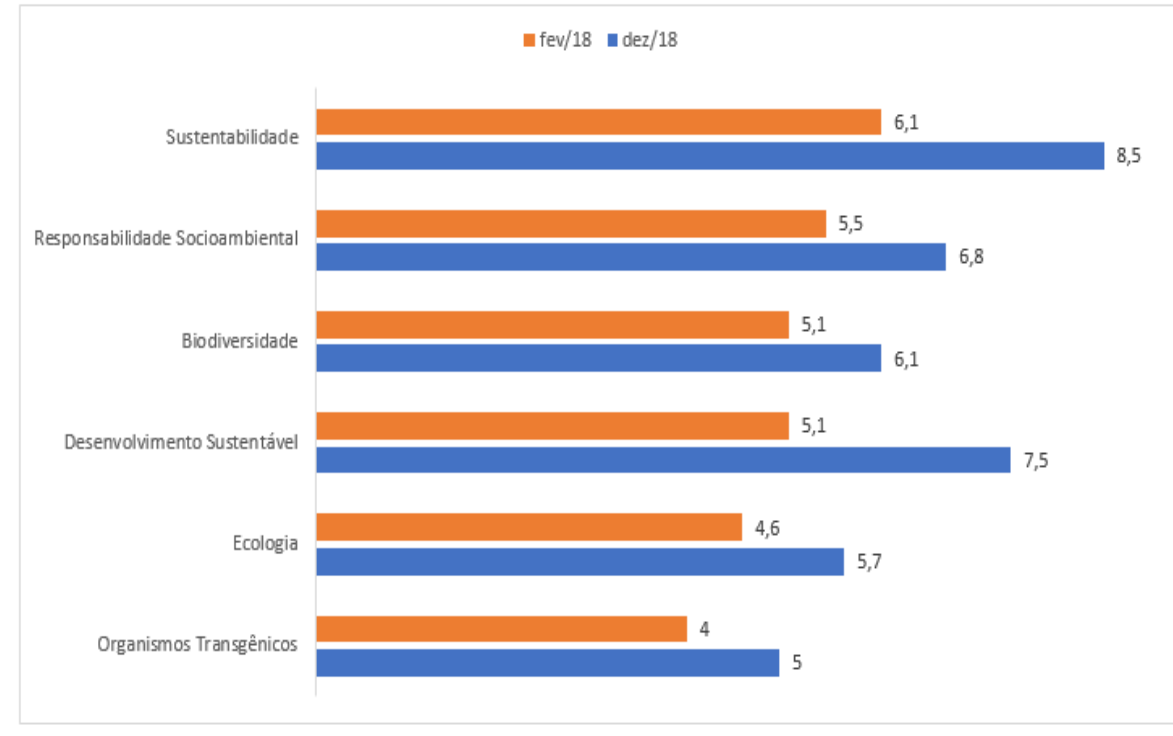

Fonte: Autor (2019)

O Gráfico 3 reflete o conhecimento das temáticas relacionadas à sustentabilidade por parte dos estudantes, antes e depois da realização do projeto. Pode-se observar que, em sua totalidade, a média da avaliação dos estudantes aumentou no questionário aplicado em dezembro de 2018, após o término do projeto. Deve-se destacar que a temática sustentabilidade, também abordada nessa questão, aumentou 2,4\% evidenciando que o projeto agregou novos conhecimentos aos estudantes. Viveiros et. al. (2015, p. 336) contribui alegando que o sujeito que adquire ou aumenta os conhecimentos sustentáveis, torna-se "apto a assumir um papel de protagonista na construção do desenvolvimento sustentável, construindo uma ética de respeito" a todos os seres sencientes ou não.

A próxima questão avaliou o conhecimento prévio dos estudantes no início das atividades (março-2018), e ao final das atividades (dezembro-2018). Desta forma foi perguntado: "Você se considera bem informado sobre questões relacionadas à sustentabilidade e ao meio ambiente?". Nessa questão, o estudante deveria escolher entre as opções "sim", "não" ou optar por não respondê-la. Desta forma, observou-se uma considerável melhoria nas respostas, conforme destaca-se no Gráfico 4. 
DOI: $10.12957 /$ e-mosaicos.2021.50343

Gráfico 4 - Você se considera bem informado sobre questões relacionadas à sustentabilidade e ao meio ambiente?

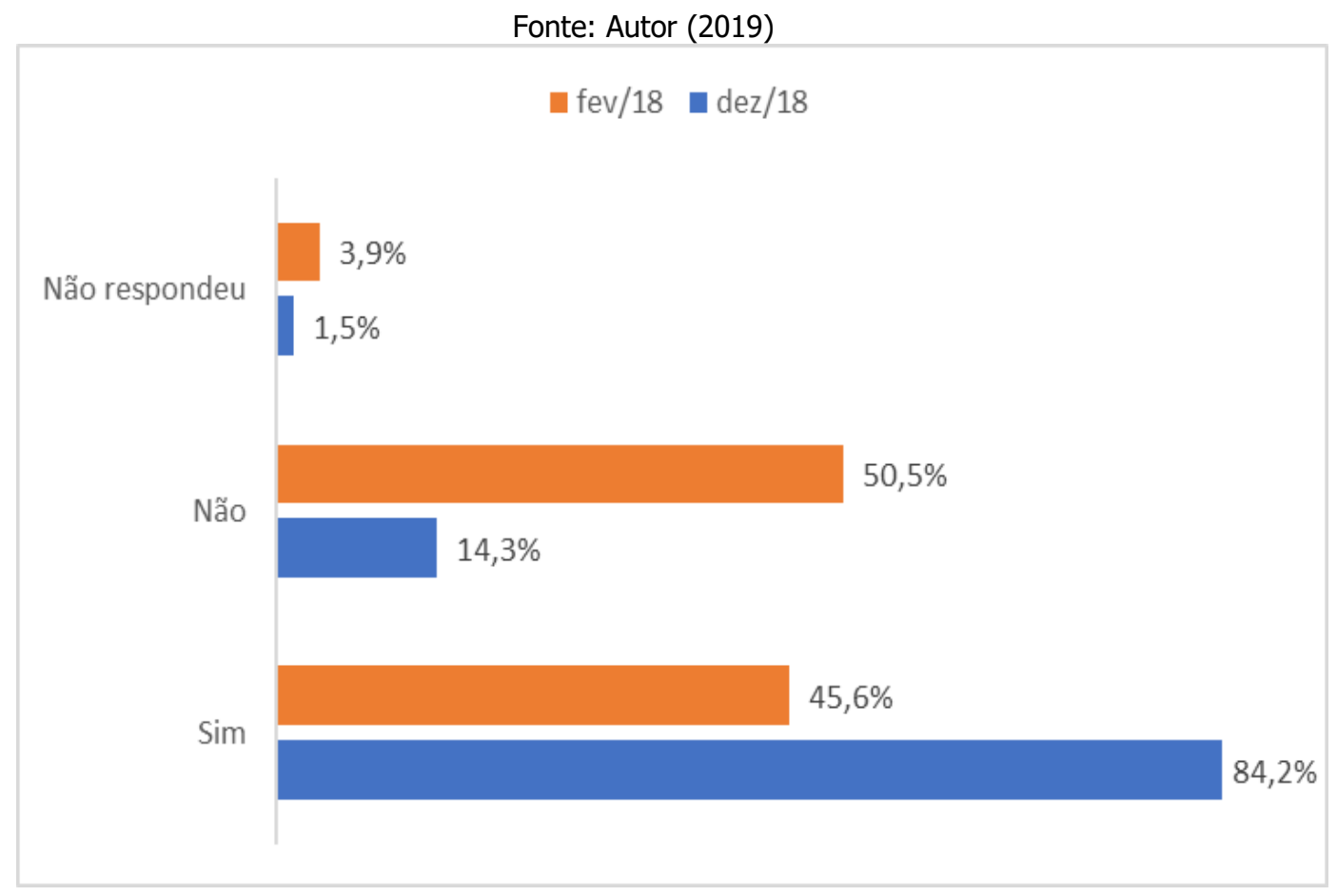

Após a autoavaliação sobre os conhecimentos relacionados à sustentabilidade, os estudantes mostraram que houve uma aprendizagem significativa com a execução do projeto. A questão onde pergunta-se sobre como eles consideram seu grau de informação relacionada à sustentabilidade e ao meio ambiente (Gráfico 4) mostra-nos que o percentual de estudantes que se consideram bem informados sobre a temática aumentou em $38,58 \%$, sendo que $84,2 \%$ se consideraram muito bem informados, viabilizando a aplicação desse projeto no construto conhecimento e educação sustentável. Os dados são consonantes às ideias de Tozoni-Reis (2008, p.158) ao afirmar que "a educação ambiental crítica se preocupa com as relações que os sujeitos estabelecem entre si e o ambiente onde vivem de forma crítica e transformadora". 
DOI: $10.12957 / \mathrm{e}-\mathrm{mosaicos} .2021 .50343$

CONSTRUTO: CONSCIÊNCIA SUSTENTÁVEL

Gráfico 5 - Onde você pratica a sustentabilidade?

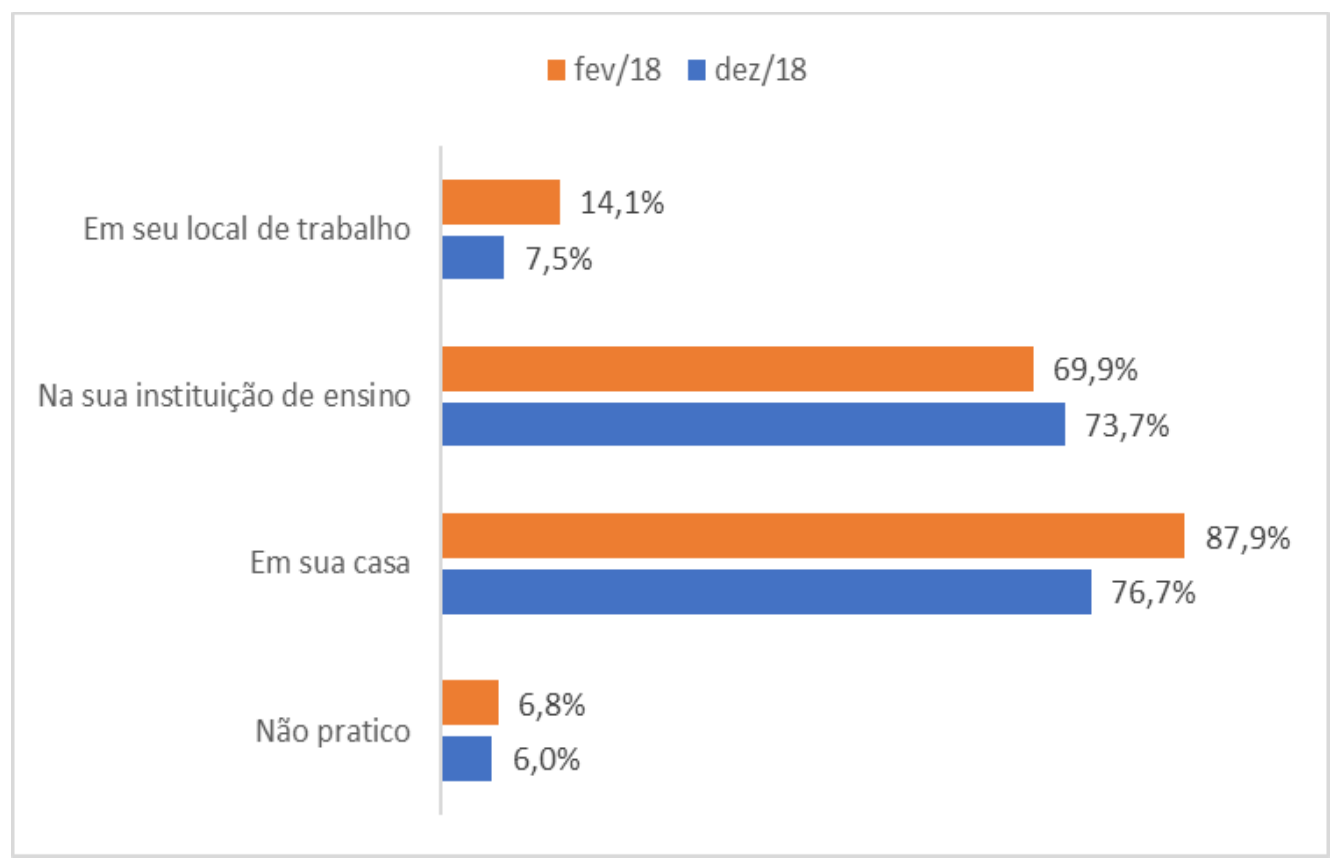

Fonte: Autor (2019)

Na questão sobre a prática da sustentabilidade (Gráfico 5), os estudantes poderiam marcar mais de uma opção onde a praticavam. Diante dos dados expostos no Gráfico 5, observa-se que a porcentagem de estudantes que pratica ações sustentáveis nas instituições de ensino aumentou em 3,78\%. Além disso, o percentual de estudantes que não praticavam nenhuma atividade sustentável reduziu em $0,78 \%$. Contudo, as ações praticadas em sua casa e no local de trabalho demonstram decréscimo no resultado, 0 que nos leva a questionar referidas somatórias. Importante lembrar que no início das atividades os estudantes não tinham conhecimentos suficientes para responder a esta questão com convicção, pois não estavam conscientes dos diversos conteúdos que permeiam a temática. Outro ponto a ser considerado sobre o decréscimo no resultado pode estar relacionado a uma visão mais apurada sobre o tema, o qual reflete respostas, no segundo momento da pesquisa, de maior lucidez e conhecimento, ao qual possibilitou 
DOI: $10.12957 /$ e-mosaicos.2021.50343

a "produção do conhecimento sobre os processos educativos ambientais" (TOZONI-REIS, 2008, p.158).

Com isso, podemos constatar que o projeto, apesar de não evidenciar uma grande alteração, serviu como um incentivo e motivação às práticas sustentáveis. Ressalta-se ainda, que promoveu nos estudantes a associação do ambiente escolar com práticas sustentáveis, incentivando essa "nova ética ambiental" construindo respeito mútuo e assumindo papel de protagonista na construção do desenvolvimento sustentável" (VIVEIROS, 2015).

Gráfico 6 - O que você faz no seu cotidiano para proteger o meio ambiente e promover a sustentabilidade?

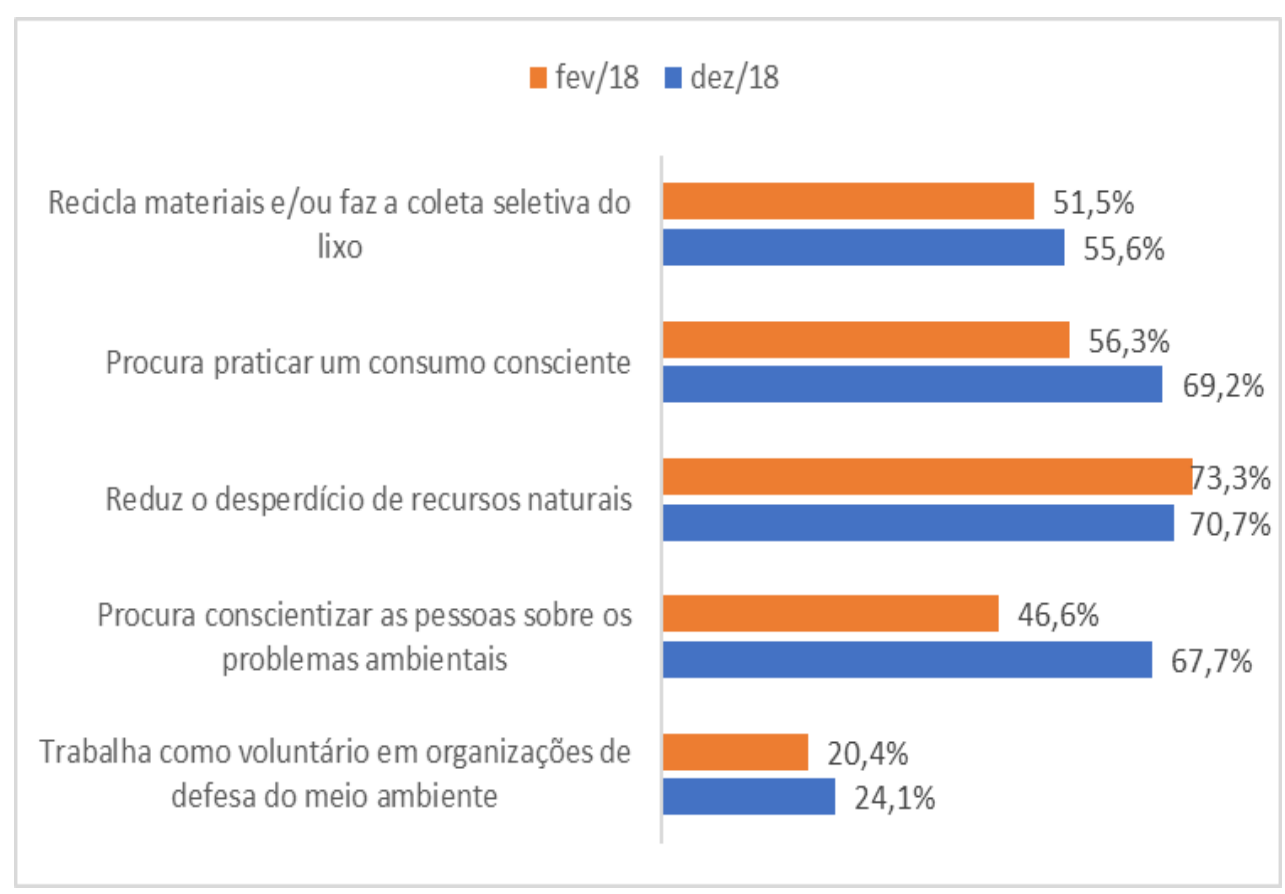

Fonte: Autor (2019)

Os dados expostos no Gráfico 6 demonstram uma significativa mudança no cotidiano dos estudantes. A porcentagem de estudantes que se envolveu com a temática proposta e transcendeu o ambiente da sala de aula, levando tais conhecimentos para os diversos contextos de sua vivência, aumentou consideravelmente com $67,7 \%$ após as intervenções, em comparação aos $46,6 \%$ anteriores às atividades. No entanto, $2,63 \%$ dos 
DOI: $10.12957 /$ e-mosaicos.2021.50343

estudantes que afirmavam reduzir o desperdício de recursos naturais não se pronunciaram dessa mesma forma no segundo questionário, o que pode levar a pensar que o estudante foi mais crítico quando questionado pela segunda vez, refletindo sobre suas práticas e reelaborando suas respostas por meio do conhecimento adquirido durante 0 ano, mostrando conscientização e conferindo "consciência ambiental e ética, valores e atitudes, técnicas e comportamento em consonância com o desenvolvimento sustentável" (BRASIL, 2002 apud VIVEIROS, 2015, p. 336).

Tabela 1 - Quais atividades você faz, rotineiramente, que utilizam água e qual o tempo gasto?

\begin{tabular}{|c|c|c|c|c|c|c|c|}
\hline & & \multicolumn{5}{|c|}{ Tempo gasto } & \multirow{2}{*}{$\begin{array}{l}\text { Quantidade total } \\
\text { de estudantes que } \\
\text { realizam a } \\
\text { atividade }\end{array}$} \\
\hline & & $5 \min$ & $10 \mathrm{~min}$ & $15 \min$ & $20 \mathrm{~min}$ & $+20 \mathrm{~min}$ & \\
\hline \multirow{2}{*}{ Tomar Banho } & MAR & $13,7 \%$ & $29,4 \%$ & $23,0 \%$ & $18,7 \%$ & $15,2 \%$ & 204 \\
\hline & DEZ & $13,5 \%$ & $41,4 \%$ & $15,8 \%$ & $9,8 \%$ & $19,5 \%$ & 133 \\
\hline \multirow{2}{*}{ Regar as plantas } & MAR & $76,4 \%$ & $16,4 \%$ & $3,6 \%$ & $3,6 \%$ & - & 55 \\
\hline & DEZ & $88,9 \%$ & $8,3 \%$ & $2,8 \%$ & - & - & 36 \\
\hline \multirow{2}{*}{ Lavar as mãos } & MAR & $89,5 \%$ & $7,0 \%$ & $1,5 \%$ & $1,0 \%$ & $1,0 \%$ & 200 \\
\hline & DEZ & $97,7 \%$ & $2,3 \%$ & - & - & - & 128 \\
\hline \multirow{2}{*}{ Lavar Roupas } & MAR & $3,7 \%$ & $13,3 \%$ & $17,8 \%$ & $21,5 \%$ & $43,7 \%$ & 135 \\
\hline & DEZ & $2,4 \%$ & $9,4 \%$ & $17,6 \%$ & $20,0 \%$ & $50,6 \%$ & 85 \\
\hline \multirow{2}{*}{$\begin{array}{l}\text { Tomar banho de } \\
\text { mangueira }\end{array}$} & MAR & $17,4 \%$ & $19,6 \%$ & $37,0 \%$ & $19,6 \%$ & $6,5 \%$ & 46 \\
\hline & DEZ & $25,8 \%$ & $32,3 \%$ & $9,7 \%$ & $9,7 \%$ & $22,6 \%$ & 31 \\
\hline \multirow{2}{*}{ Lavar a louça } & MAR & $15,2 \%$ & $30,9 \%$ & $28,8 \%$ & $12,6 \%$ & $12,6 \%$ & 191 \\
\hline & DEZ & $17,9 \%$ & $39,8 \%$ & $26,8 \%$ & $9,8 \%$ & $5,7 \%$ & 123 \\
\hline \multirow{2}{*}{ Escovar os Dentes } & MAR & $65,5 \%$ & $25,5 \%$ & $6,5 \%$ & $1,5 \%$ & $1,0 \%$ & 200 \\
\hline & DEZ & $84,6 \%$ & $13,1 \%$ & $2,30 \%$ & - & - & 130 \\
\hline \multirow{2}{*}{ Lavar a Bicicleta } & MAR & $27,6 \%$ & $28,9 \%$ & $21,1 \%$ & $10,5 \%$ & $11,9 \%$ & 76 \\
\hline & DEZ & $28,3 \%$ & $39,6 \%$ & $15,1 \%$ & $15,1 \%$ & $1,9 \%$ & 53 \\
\hline
\end{tabular}

Fonte: Autor (2019)

A Tabela 1, referente aos dados obtidos com questão sobre o tempo gasto em diversas atividades com o uso da água, permite-nos observar a efetivação prática do projeto sustentabilidade na vivência dos estudantes. Nota-se que nas atividades: lavar as mãos, regar as plantas, lavar a louça, escovar os dentes e lavar a bicicleta, o tempo gasto realizando tais práticas que dispendem água foi reduzido, evidenciando que a maior parte da amostra pesquisada realiza tais funções em até 5 minutos. No entanto, o hábito de tomar banho obteve conclusões divergentes com essas respostas até o momento. 
DOI: $10.12957 /$ e-mosaicos.2021.50343

Constatou-se que tal prática resultou em um tempo gasto superior a 20 minutos. Esse hábito mostra-se preocupante, pois além de gerar um desperdício de água, banhos muito longos geram, também, o desperdício de energia.

Gráfico 7 - O que você faz com o lixo de sua casa?

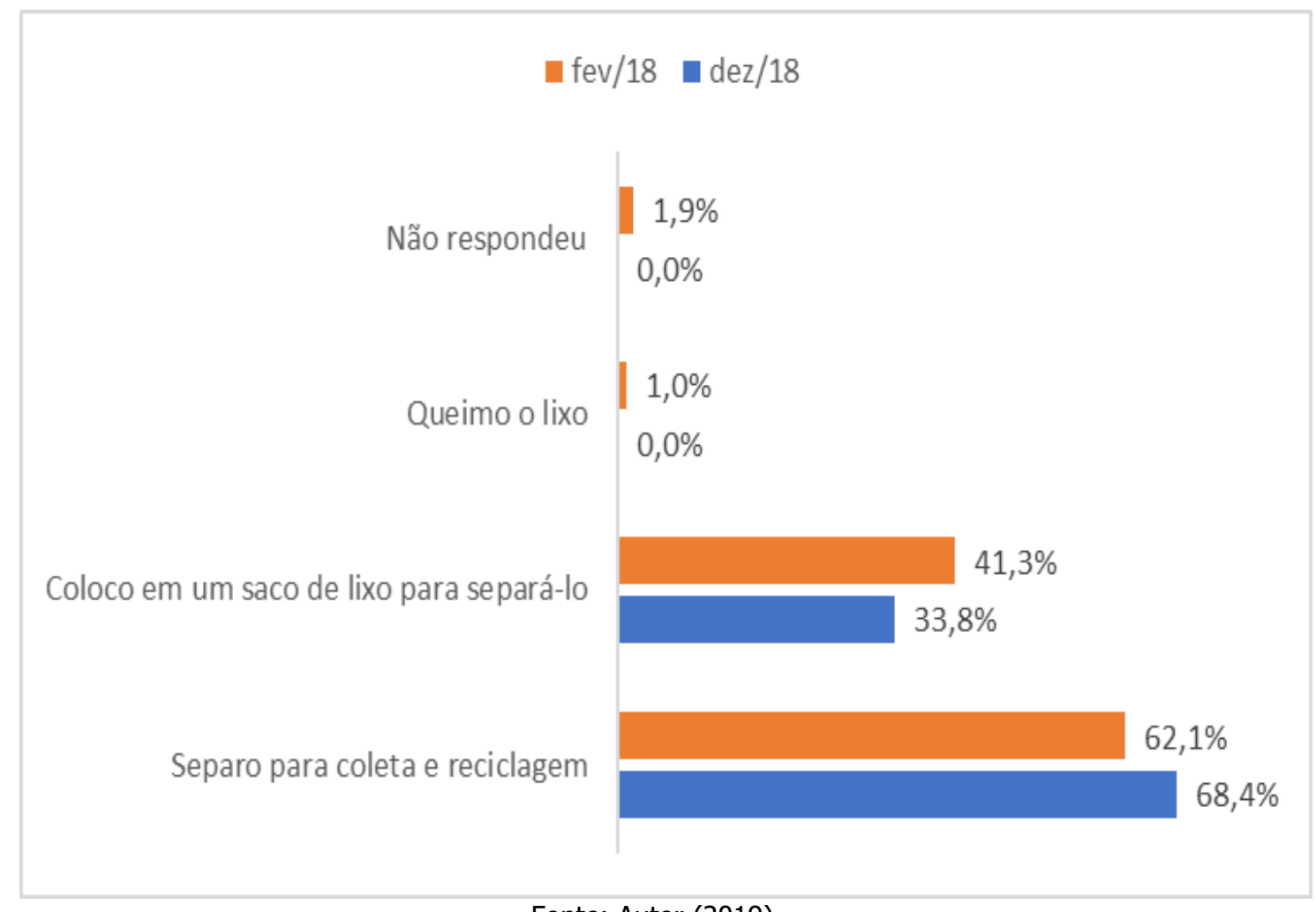

Fonte: Autor (2019)

A questão exibida no Gráfico 7 que se propôs a entender o que cada estudante faz com o lixo de sua casa reflete efeitos positivos na sua conduta sustentável, mostrando um aumento percentual no número de estudantes que passaram a separar o lixo para coleta e reciclagem, bem como os que colocam em sacos de lixo para realizar a separação. Além disso, o percentual de estudantes que queimam o lixo ou deixaram de responder a essa questão no primeiro questionário reduziu-se a zero. Constata-se aqui as tomadas de decisões éticas afirmadas por Carramillo-Going e Cortella (2017, p. 120) como a "clarificação de valores e a construção de uma identidade ecológica" capazes de análise crítica e tomada de decisão consciente frente à situação exposta. 
DOI: $10.12957 /$ e-mosaicos.2021.50343

Gráfico 8 - O que você faz com os objetos que já não usa mais?

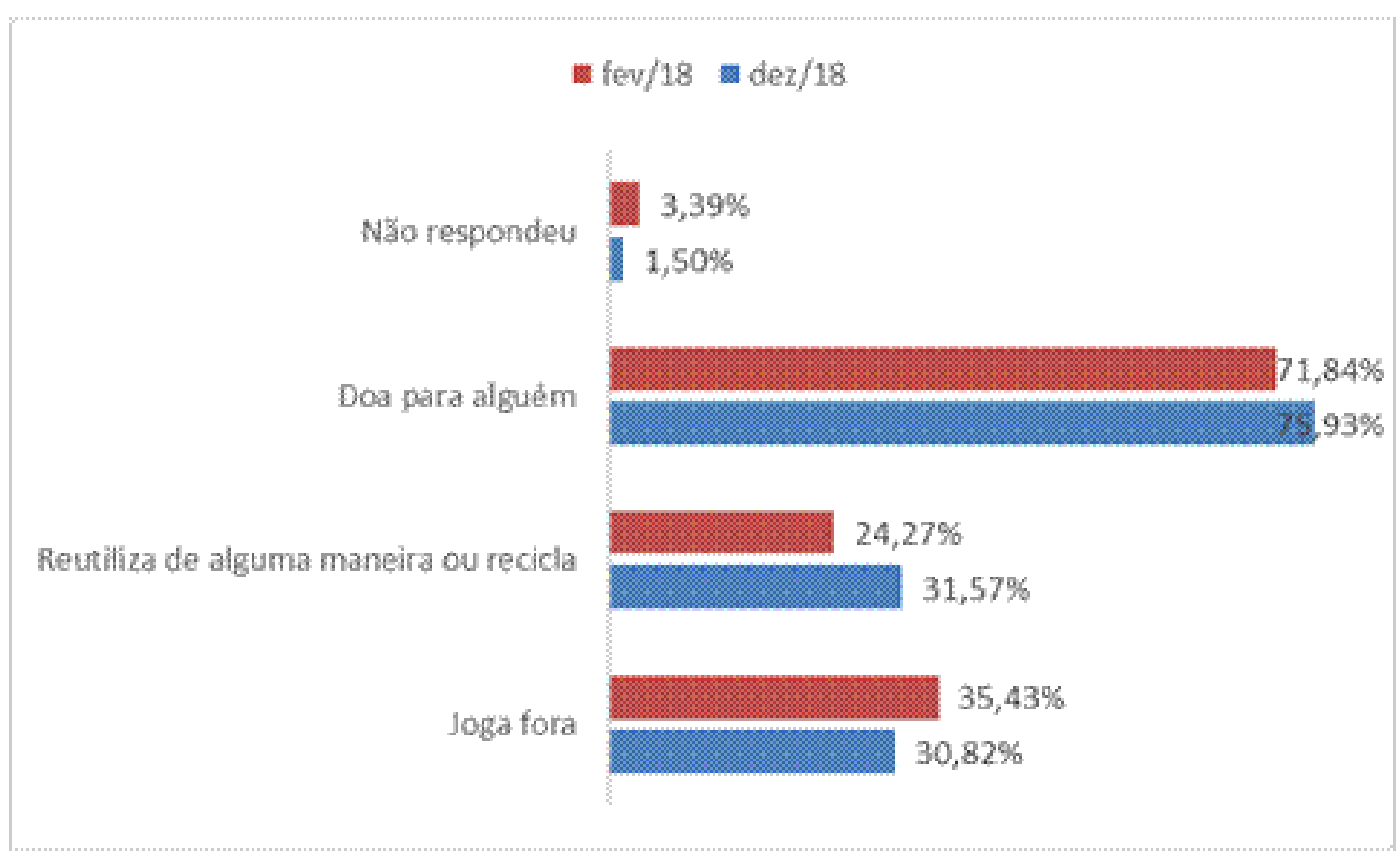

Fonte: Autor (2019)

Os dados expostos no Gráfico 8 mostram uma significativa melhora na conduta sustentável dos estudantes. Enquanto o valor percentual de estudantes que jogavam fora os objetos que não usavam mais foi reduzido em $5 \%$, os percentuais de reutilização $(31,57 \%)$ e doação $(75,9 \%)$ tiveram um aumento significativo. É possível afirmar que os alunos, devido à sua cultura, já doavam ou reutilizavam seus pertences, porém, agora o fazem com consciência ambiental, refletindo sobre suas ações frente ao planeta (CARRAMILLO-GOING; CORTELLA, 2017).

Acrescentou-se, ainda, ao questionário aplicado em dezembro de 2018 uma questão de caráter dissertativo, que propunha a reflexão sobre quais mudanças de hábitos foram incorporadas ao cotidiano dos estudantes que colaboram com a sustentabilidade e o meio ambiente. Tal questão evidenciou diversas mudanças, entre elas: a diminuição do descarte de lixo; diminuição do desperdício de água e energia; não utilizar mais canudos ou sacolas plásticas; separar o lixo corretamente e destiná-lo à reciclagem; conscientizar as demais pessoas; consumir de forma consciente; comprar produtos com o selo de sustentabilidade; diminuição no tempo de banho. 
DOI: $10.12957 /$ e-mosaicos.2021.50343

\section{CONSIDERAÇÕES FINAIS}

Com este trabalho podemos perceber como a evolução da humanidade e da tecnologia impactaram negativamente o meio ambiente. A sustentabilidade entrou neste cenário sendo uma maneira de minimizar os efeitos negativos que causamos. Deste modo podemos produzir de maneira sustentável, cuidando para que as gerações futuras também desfrutem dos recursos naturais que temos.

A educação ambiental com enfoque na sustentabilidade tornou-se uma estratégia eficaz na efetivação da nova ética ambiental que o cenário contemporâneo nos apresenta. Uma ética na qual a consciência cidadã a respeito dos problemas ambientais e a próatividade em refletir e buscar soluções viáveis para tais impasses mostram-se como eixos centrais para o desenvolvimento sustentável. As escolas e instituições de ensino ao abordarem a temática sustentabilidade permitem-se transcender ao formar não apenas estudantes, mas sim cidadãos conscientes e ativos em sociedade.

Analisando os resultados obtidos com os questionários aplicados pode-se perceber que o projeto sustentabilidade trouxe mudanças significativas para a vida cotidiana dos estudantes. A reformulação de diversos hábitos visando a promoção da sustentabilidade resultou na reflexão sobre as consequências do uso indiscriminado dos recursos naturais. Tal reflexão foi incentivada nos momentos propostos em sala de aula durante a execução do projeto.

Deve-se mencionar ainda, que o projeto serviu como inspiração e motivação aos estudantes para adotarem um posicionamento sustentável com ações que visem à preservação do meio ambiente. No entanto, a temática sustentabilidade não deve estar restrita somente a esses momentos propostos, mas sim ser trabalhada de forma continuada durante todos os anos escolares de maneira interdisciplinar. Deve-se considerar, ainda, que os dados obtidos nessa pesquisa não são conclusivos, apenas servem de estímulo para que novas pesquisas e projetos referentes à temática sejam elaborados.

\section{REFERÊNCIAS}

BARBIERI, José Carlos; SILVA, Dirceu da. Desenvolvimento sustentável e educação ambiental: uma trajetória comum com muitos desafios. Revista de Administração Mackenzie, São Paulo, v. 12, n. 3, p.51-82, jun. 2011. Disponível em: http://www.scielo.br/scielo.php?pid=S1678-

69712011000300004\&script=sci_abstract\&tlng=pt. Acesso em: 09 fev. 2019. 
DOI: $10.12957 / \mathrm{e}-\mathrm{mosaicos} .2021 .50343$

BOFF, Leonardo. Sustentabilidade: O Que É, O Que Não É. Petrópolis, RJ: Vozes, 2012. $200 \mathrm{p}$.

CAPRA, F. et al. Alfabetização ecológica: a educação das crianças para um mundo sustentável. São Paulo, Cultrix. 2006.

CARRAMILLO-GOING, Luana Carramillo; CORTELLA, Mário Sérgio. Educação Ambiental e o Compromisso Profissional com a Sociedade na Visão de Paulo Freire. e-Mosaicos - Revista Multidisciplinar de Ensino, Pesquisa, Extensão e Cultura (CAp-UERJ). 2017. v.6, n.13., p. 112-125. ISSN: 2316-9303. Doi: http:\10.12957/e-mosaicos.2017.30814.

CNUMAH. Declaração de Estocolmo sobre o ambiente humano. Estocolomo, 1972. Disponível http://www.educacaoambiental.pro.br/victor/unidades/DeclaraAmbienteHumano.pdf. Acesso em: 09 fev. 2019.

SILVA, Christian Luiz da; MENDES, Judas Tadeu Grassi (orgs.). Reflexões sobre $o$ desenvo/vimento: agentes e interações sobre a ótica multidisciplinar. Petrópolis: Vozes, 2005.

DIAS, G. F. Educação ambiental, princípios e práticas. 8.ed. Gaia, 2003.

GADOTTI, Moacir. Educar para a sustentabilidade: uma contribuição à década da educação para o desenvolvimento sustentável / Moacir Gadotti. - São Paulo: Editora e Livraria Instituto Paulo Freire, 2008. - (Série Unifreire; 2).

GIL, Antonio Carlos. Como elaborar projetos de pesquisa. 5.ed - São Paulo: Atlas, 2010.

GOTTARDO R. M. S. A Educação Ambiental no Contexto da Secretaria Municipal de Educação: um estudo de caso do período 1977 a 2000. 2003. Dissertação (Mestrado). Universidade Presbiteriana Mackenzie. São Paulo.

HOFFMANN, Allan; LAMAS, Nadja de Carvalho; WESTPHAL, Euler Renato. Aproximações da Trilha da Vida à uma abordagem fenomenológica. Revista Eletrônica do Mestrado em Educação Ambiental, vol. 36, n.2, pp. 342-358, 2019. ISSN 1517-1256.

LAKATOS, Eva Maria; MARCONI, Marina de Andrade. Fundamentos metodologia científica. 4.ed. São Paulo: Atlas, 2001. 
DOI: $10.12957 / \mathrm{e}-\mathrm{mosaicos} .2021 .50343$

RICHARDSON, Roberto Jarry. Pesquisa Social: métodos e técnicas - 3. Ed. - 15 reimpr. São Paulo: Atlas, 2014.

PEREIRA, André Luiz, et al. Logística Reversa e Sustentabilidade. São Paulo: Cengage Learning, 2013.

VALLE, Rogerio; SOUZA, Ricardo Gabbay de. Logística Reversa: processo a processo. São Paulo: Atlas, 2014.

VIVEIROS, Edna Parizzi de; MIRANDA, Maria Geralda de; NOVAES, Ana Maria Pires e AVELAR, Kátia Eliane Santos. Por uma nova ética ambiental. Eng. Sanit. Ambient. [online]. 2015, vol.20, n.3, pp.331-336. ISSN 1413-4152. http://dx.doi.org/10.1590/S141341522015020000114401.

TOZONI-REIS, Marília Freitas de Campos. Pesquisa-ação em Educação Ambiental. Pesquisa em Educação Ambiental, n.1, pp. 155-169, 2008.

Recebido em 20 de abril de 2020 Aceito em 18 de fevereiro de 2021

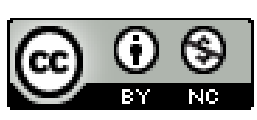

A e-Mosaicos Revista Multidisciplinar de Ensino, Pesquisa, Extensão e Cultura do Instituto de Aplicação Fernando Rodrigues da Silveira (CAp-UERJ) está disponibilizada sob uma Licença Creative Commons - Atribuição - NãoComercial 4.0 Internacional.

Os direitos autorais de todos os trabalhos publicados na revista pertencem ao(s) seu(s) autor(es) e coautor(es), com o direito de primeira publicação cedido à e-Mosaicos.

Os artigos publicados são de acesso público, de uso gratuito, com atribuição de autoria obrigatória, para aplicações de finalidade educacional e não-comercial, de acordo com o modelo de licenciamento Creative Commons adotado pela revista. 